\title{
Adherence to prescriptions of therapeutic exercises in patients with traumatic spinal cord injury
}

\author{
Justyna Frasuńska ${ }^{1, A-D, F \oplus}$, Piotr Wojdasiewicz ${ }^{2, E-F \oplus}$, Piotr Tederko ${ }^{1, C, E \oplus}{ }^{\oplus}$ Krzysztof Wasiak $^{3, B \oplus}$, \\ Beata Tarnacka ${ }^{1, A, C, E-F \odot ~}$ \\ ${ }^{1}$ Medical University, Warsaw, Poland \\ ${ }^{2}$ National Institute of Geriatrics, Rheumatology and Rehabilitation, Warsaw, Poland \\ ${ }^{3}$ Mazovian Rehabilitation Center STOCER, Konstancin-Jeziorna, Poland \\ A - Research concept and design, B - Collection and/or assembly of data, C - Data analysis and interpretation, \\ $D$ - Writing the article, E-Critical revision of the article, F- Final approval of article
}

Frasuńska J, Wojdasiewicz P, Tederko P, Wasiak K, Tarnacka B. Adherence to prescriptions of therapeutic exercises in patients with traumatic spinal cord injury. Ann Agric Environ Med. 2021; 28(2): 331-338. doi: 10.26444/aaem/119941

\section{Abstract}

Introduction and objective. Spinal cord injury $(\mathrm{SCl})$, which disrupts motor, sensory and autonomic functions, causes significant changes in the functioning of an individual. It is believed that most of the conditions secondary to $\mathrm{SCl}$, i.e. osteoporosis, spasticity or cardiopulmonary diseases, are associated with immobility. The aim of the study is to assess the adherence to prescriptions of therapeutic exercises (APTE) in patients with SCl after acute phases of rehabilitation.

Materials and methods. The criterionfor APTE recognition was the performance at least twice a week for a minimum of 30 minutes of active exercises with resistance, and exercises maintaining the range of movement of the joints The research tools were own questionnaire and the WHOQOL-BREF scale.

Results. 46 subjects (63.9\%) met the APTE criteria. The most frequent place for performing the exercises was the subject's home with 43 subjects (93.5\%) with APTE performed the exercises in their homes. 17 subjects (36.9\%) with APTE performed exercises during stays at various rehabilitation centres. The main cause for the lack of APTE was the limited availability of facilities considered necessary by the respondents to adhere to the instructions. In statistical analysis, the level of neurological injury correlated with meeting the APTE criteria. It was discovered that a subjective assessment of the exercise dose correlated with the place where the exercises were performed, but did not correlate with meeting the APTE criteria.

Conclusions. The basic place for performing exercises (as instructed in hospital) was the subject's home. Limited access to reimbursed environmental therapy resulted in an increased cost of exercises supervised by commercially-employed physiotherapists. The current gaps in the system of supervision and counselling of subjects post-SCI necessitate changes in the Polish health care system.

Key words

rehabilitation, life quality, spinal cord injury, exercise, observational study

\section{INTRODUCTION}

Spinal cord injury (SCI), by disrupting motor, sensory and autonomic functions, and increased risk of secondary health conditions, causes changes in the functioning of an individual [1]. Important objectives of the rehabilitation programme include recovery to the highest possible level of fitness and activity, and participation in social and professional life. Therapeutic exercises play an important role in reaching this objective [2].

Currently, an increase is being observed in the number of subjects with physical disability secondary to SCI, longer survival and a gradual reduction in time spent in hospital by patients after acute SCI at rehabilitation departments [3]. Subjects with SCI are characterized by an increased risk of osteoporosis, cardiopulmonary diseases, and the development of spasticity and contractures [4]. It is believed that most of the conditions secondary to SCI are associated with immobility which results in the escalation of health

Address for correspondence: Justyna Frasuńska, Medical University, Warsaw, Poland E-mail: frasunska@gmail.com

Received: 17.12.2019; accepted: 30.03.2020; first published: 21.04 .2020 needs, including rehabilitation needs, and emphasis the importance of exercises performed by an SCI patient following rehabilitation in the acute phase facility. Adherence to therapeutic exercises prescribed by a physiotherapist (being part of a complex rehabilitation programme) is an important factor which may affect the long-term treatment outcome [5-11]. As recommended in 2015 by the American Congress of Rehabilitation Medicine, the exercise programme should be continued, including resistance and aerobic training, for not less than 30 minutes twice a week, as well as every day for 5-15 minutes of stretching exercises and exercises maintaining the range of motion for maintaining the vertical body position [12].

Adequate exercise instructions, ergonomics, and inclusion of exercises in the patient's everyday habit largely depends on self-control, which is the result of perceiving and handling the disease and selection of activities implied by assessment of potential treatment outcomes [13]. Adherence to the prescriptions of therapeutic exercises (APTE) is an important distinctive feature of the efficacy of medical intervention, especially rehabilitation [14]. According to research by the authors of the current study, no studies have been conducted in the European Union on APTE in SCI subjects. On the 
basis of studies conducted in the USA and Canada with study groups of between 7-34 participants, it may be concluded that in those countries, APTE in subjects with SCI consequences ranges from 42.7-80.6\% [15-20]. A correlation between APTE and improvement in the quality of life (QOL) was confirmed $[19,20]$. APTE shows an inverse correlation with age $[18]$ and pain intensity $[18,20]$. There are contradictory data regarding a correlation between APTE and time after hospital discharge $[18,20]$.

Accruing more knowledge concerning APTE may be helpful in identifying patients at an increased risk of nonadherence to hospital guidelines and its consequences. The identification of factors making it difficult to adhere to the guidelines will deepen the knowledge on the lifestyle of SCI subjects, and may support the planning efficacy of health care programmes for these patients.

In Poland, early neurological rehabilitation after SCI begins within 14 days after leaving the rehabilitation centre and lasts for up to 12 weeks, or 16 weeks with concomitant diseases that may affect the treatment process. After the rehabilitation, the patients return home with instructions to continue the recommended exercise programme [12]. Extending State-financed rehabilitation treatment is often difficult to achieve, and for this reason the determination of some patients to recover is often associated with commercial rehabilitation. According to Dietz V [21], gait re-education of patients with incomplete spinal cord injury, especially during the first year after injury, is justified. Unfortunately, in Poland there is no standardized care programme for patients after SCI, taking into account all patients health needs. A year after injury, the patient begins environmental and occupational rehabilitation, which is carried out by governmental and non-governmental organizations.

\section{OBJECTIVE}

The aim of the study was to assess APTE in patients with traumatic SCI after completion of acute and post-acute phases of rehabilitation.

\section{MATERIALS AND METHODS}

The current retrospective, observational study is a part of the programme 'SCI Patient Histories' which covers a broad scope of issues, including social, vocational, health, and the financial problems of subjects post-SCI. The study was approval by the Bioethics Committee (No. KB 926/14) of the Regional Medical Chamber in Warsaw, Poland. Basic personal data, i.e.: name, gender, date of birth, address, diagnoses, causes of injury, and date of last hospitalization, were downloaded from the MCR STOCER database in Konstancin Jeziorna, near Warsaw. The research tools were own questionnaire and the WHOQOL-BREF scale [22]. The criterion of APTE recognition was the performance of active resistance and aerobic exercises and range of motion exercises for a minimum of 30 minutes at least twice a week. The presented study describes APTE, places of implementation of the instructions, and the participation of other people (family members, qualified professionals) in the participant's performance of exercises. The causes of non-APTE were studied by asking close-ended questions; the list of causes included: lack of willingness to perform exercises, health problems, distance to a rehabilitation centre, lack of transport, and the cost of a physiotherapy service. Respondents also had the possibility to complete the list by providing other causes. The information concerning the funding sources of paid physiotherapy services related to APTE was obtained by means of closed multiple choice questions.

Analysis involved a study of the correlations between APTE and selected parameters of body structures and functions:

- injury level, presence of pressure ulcers during the study, presence of spasticity observed at hospital discharge above 1 in the Modified Ashworth Scale;

- personal and environmental factors:

- gender, age, marital status, economic situation, and sense of security in everyday life; - activity and participation of subjects with SCI, activity according to the Barthel scale [23];

- assessment of walking function with WISCI-II [24];

- level of readiness to act;

- professional activity, performance of daily activities;

- QOL and economic situation of the study own questionnaires, WHOQOL-BREF scale) [22].

The Barthel scale was also used which contains 20 questions and determines the activities of daily living [23] and the Walking Index for SCI (WISCI-II), which determines mobility possibilities with or without rehabilitation equipment [24]. The WHOQOL-BREF scale consists of 26 questions and includes four domains of QOL: physical health, psychological, social relationships and environment [22]. This questionnaire was relevant regarding the necessity of treatment, self-acceptance, sense of security, ability to perform the ADL, and readiness to act. Analysis based on these points allowed the presentation of APTE in relation to selected personal and environmental factors.

Inclusion criteria allow the involvement of patients after traumatic SCI qualified to ASIA Impairment Scale (AIS) groups $A, B, C, D$ [25] who had been discharged from the department of neurological rehabilitation after completion of the acute and post-acute phase, within a minimum of 10 months after leaving the centre (hospital discharge between 1 April 2011-31 December 2014). Exclusion criteria included non-traumatic SCI and co-morbidities that could affect the conclusions and non-compliance with the criteria, e.g. mental illness, severe head injuries.

Participation in the study was voluntary. Each patient who agreed to participate completed and signed an official consent form. The questionnaires were sent to the patients by post. If no reply was received, the subjects were contacted by telephone or e-mail, or the information was obtained during a personal contact with the intended study subject.

Before hospital discharge, each patient received oral instructions concerning exercises, combined with an educational session consolidating the ability to perform the prescribed techniques without assistance. Recommendations were provided individually to patients, according to their needs and possibilities. Each patient was also told to continue the exercises learned at discharge from hospital, not less than twice a week for 30 minutes of aerobic and strength exercises, as instructed $[12,26]$. The patients were instructed to continue the exercise programme either by themselves or with the assistance of another person. 
Statistical analysis of the collected data was based on the methods of descriptive statistics: rate, percentage, arithmetic mean, minimum, maximum and standard deviation. Comparisons between the groups were performed with the use of the Chi-square test or (in the case of comparing rare events) the Fisher exact test. The analysis was performed with the use of statistical software R 3.5.1 (R Core Team (2018). $\mathrm{R}$ : A language and environment for statistical computing. R Foundation for Statistical Computing, Vienna, Austria. URL https://www.R-project.org/).

General characteristics of the study group. 104 patients meeting the inclusion criteria were sent questionnaires by post and replies were received from 60 subjects. After attempting telephone and/or an e-mail contact, questionnaires from another 12 subjects were received. Regarding the group of subjects who did not provide answers, it was established that 6 had died and 9 had changed their contact details which had precluded all contact with them. No replies were received from 26 patients (25\%).

Finally, 72 subjects were enrolled in the study all of whom were patients with physical disability after traumatic SCI. The participants (14 females and 58 males) ranged in age from 17-78-years-old, with a mean of 40,18. All respondents were of Polish nationality and living at home; $37.5 \%$ of patients with SCI resided in village and $18.06 \%$ in a small city/town, and $44.44 \%$ in a big city/town. Most of the participants had secondary education (63.89\%) and were married (56.95\%). Additionally, 39 participants had paraplegia and 33 had tetraplegia (paraplegia). The sociodemographic characteristics of the group, their functional status at discharge from hospital, and e causes of SCI are presented in Table 1.

\section{RESULTS}

In the study group, 46 subjects (63.9\%) met the APTE criteria. The most frequent place of performing exercises was the subject's home: 43 subjects (93.5\%) with APTE performed exercises at home, including $20(47.8 \%)$ who did exercises alone or with a family member and/or physiotherapist only at home, without attending physiotherapy at rehabilitation centres. In the home setting, the exercises were performed with physiotherapists financed by individuals ( $\mathrm{N}=27 ; 58.7 \%$ subjects with APTE), physiotherapist financed by State health care $(\mathrm{N}=13 ; 28.3 \%$ subjects with APTE), or family members $(\mathrm{N}=9 ; 19.5 \%$ subjects with APTE). Unassisted exercises at home were performed by 23 study subjects $(50.0 \%$ subjects with APTE).

26 subjects (56.5\% subjects with APTE) performed exercises at rehabilitation centres that were paid either by an individual, or reimbursed. 3 subjects reported that they did not perform any exercises at home. Exercises also took place at commercial rehabilitation centres $(\mathrm{N}=19 ; 41.3 \%$ subjects with APTE) and those financed by State health care ( $\mathrm{N}=21 ; 46.78,3 \%$ subjects with APTE). 14 patients (30.4\% of people with APTE) performed some exercises at both types of centres. The patients stayed at the centres either in an inpatient or outpatient setting.

The causes of non-APTE reported by respondents were: - too high cost of a physiotherapeutic service ( $N=12 ; 46.2 \%$ subjects without APTE);
- problems with transport to a rehabilitation centre $(\mathrm{N}=11$; 42.3\% subjects without APTE);

- long distance to the rehabilitation centre ( $N=11 ; 42.3 \%$ subjects without APTE);

- long waiting time for rehabilitation $(\mathrm{N}=8 ; 30.8 \%$ subjects without APTE);

- no interest in the programme due to perceived inefficacy $(\mathrm{N}=5 ; 19.2 \%$ subjects without APTE);

- poor health ( $\mathrm{N}=2 ; 7.7 \%$ subjects without APTE);

- other $(\mathrm{N}=4 ; 15.4 \%$ subjects without APTE).

The correlations between APTE and selected factors determining structures and functions, activity and participation, personal and environmental factors and components of subjective assessment of the QOL, and wellbeing by the patient are shown in Table 2. On the basis of the WHOQOL-BREF scale, the lowest score was achieved by patients for social functioning (means $=9.54 ; \mathrm{SD}=2.23$ ), while the highest score was achieved in environmental functioning (means=25.04; $\mathrm{SD}=4.75$ ). Extended analysis showed no statistical significance $(\mathrm{p}<0.05)$ in correlation between APTE and QOL components described in the WHOQOL-BREF scale. The $\mathrm{p}$-values in the Student test were, respectively: $\mathrm{p}=0.860$ for physical dominant, $\mathrm{p}=0.464$ for psychological dominant, $\mathrm{p}=0.063$ for social dominant, and $\mathrm{p}=0.806$ for environmental dominant.

A correlation between a subjectively-assessed dose of exercises in relation to needs, and the place of performing exercises with the source of financing assistance is shown in Table 3.

As part of APTE, 30 subjects (65.2\% of the group with APTE) used the services of a commercial physiotherapist. Financial resources used for this purpose mainly include own funds (savings) (37 cases, $80.4 \%$ of the group with APTE), and 3 participants (6.5\%) stated that they use family funds. 4 subjects $(8.7 \%)$ stated that their sources of APTE financing were public funds - government organisations. Other sources of financing included funds from nongovernment organizations: 5 participants (10.9\%), private loans from banking institutions -3 participants (6.5\%) and from individual persons -4 participants $(8.7 \%)$.

\section{DISCUSSION}

To the authors' best knowledge, the presented study is the first APTE analysis of SCI subjects in the countries of the European Union and covers more cases than previous studies on APTE [11-16]. A unique aspect of the study is the presentation of the correlation between APTE and medical problems, such as spasticity, pressure ulcers, and correlations with selected factors of activity and participation. APTE analysis in the available literature is based on interventional studies [15-20], none of which included an observational approach to APTE, as used in the current study.

In the analysed population, the main causes of non-APTE were unavailability of the facilities considered necessary by the respondents to adhere to the instructions, high cost of physiotherapy services in relation to the subject's income, distance to rehabilitation centres and lack of transport, as well as long waiting time for rehabilitation. Palletier et al. and Hicks et al. emphasise the significance of the problem with transport to the rehabilitation centre as a factor of non- 
Table 1. Characteristics of the study group at discharge from hospital $(N=72)$

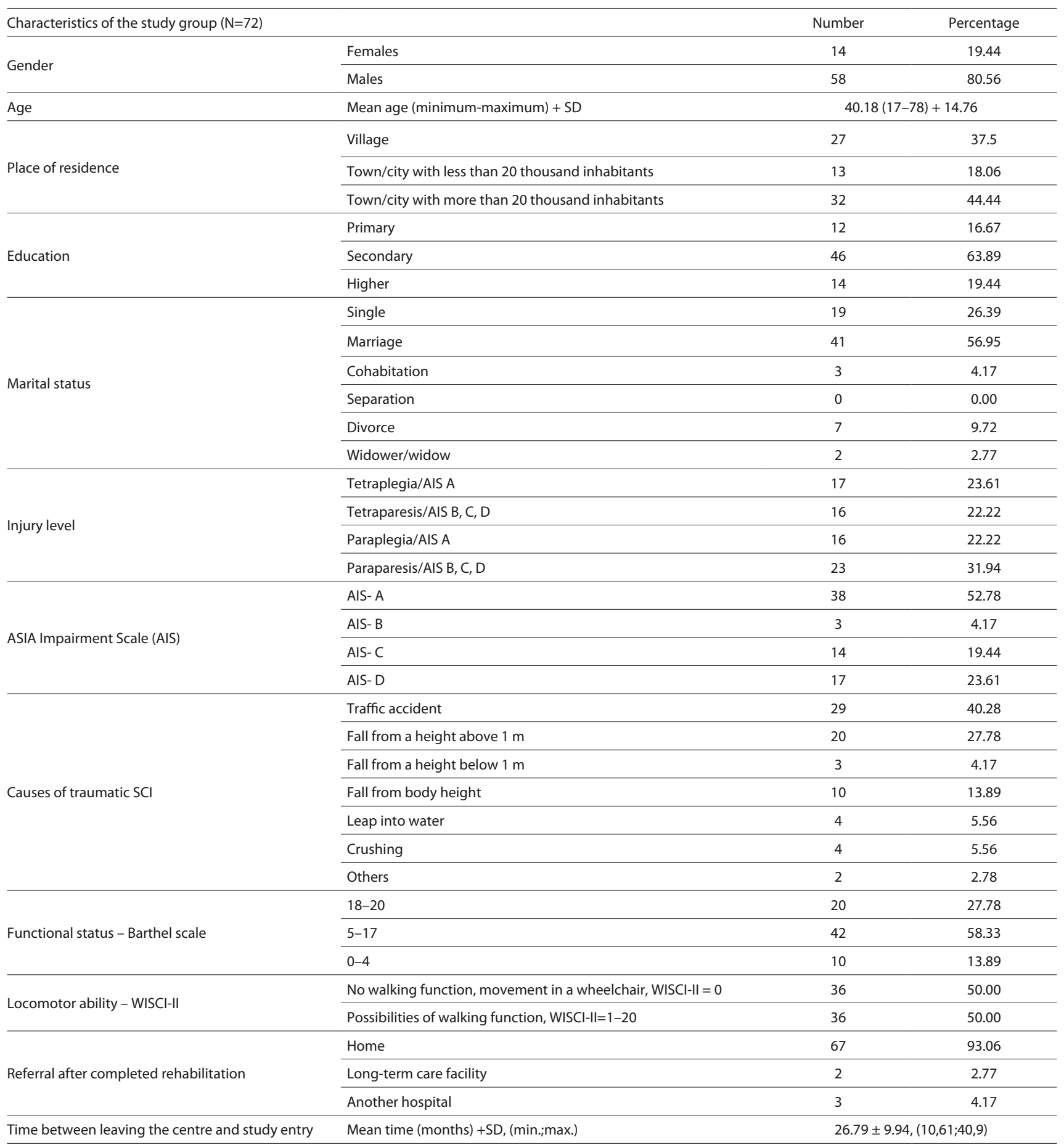

AIS - American Spinal Cord Injury Impairment Scale; ASIA - American Spinal Cord Injury; SCI - spinal cord injury; SD - standard deviation; WISCI-II - Walking Index Spinal Cord Injury - version 2.

APTE $[16,17,19]$, and according to Hicks et al., this is the most common cause [19]. However, in the studies by Palletier et al., the main cause of non-APTE was health problems $[16,17]$. In the current study, poor health was perceived as a reason for non-APTE in only 2 respondents (4.3\%). The differences between our results and the results of both studies by Palletier et al. could be explained by the fact that the participants of the studies conducted by these authors were regularly monitored (at constant intervals). Regarding the study by Palletier et al. in 2014, the subjects additionally received constant counselling and support in the follow-up period via telephone consultations. In the case of the studies by Hicks et al., despite using the criteria excluding patients with comorbidities, there was a longer follow-up period of up to 24 years after SCI. Such a long follow-up period (between 6-24 times longer than that in the current study) may have involved a higher incidence of secondary health conditions. Dolbow et al. indicate lack of interest and technical problems (with exercise equipment) as the main causes of non-APTE [18]. In the report by Dolbow et al., exercises were performed only with the use of a cycloergometer, which explains a large part of the technical problems among the causes of non- 
Table 2. Correlations between APTE and selected functional parameters, personal and environmental parameters, and the components of the quality of life and well-being (on the basis of the WHOQOL-Breef scale).

\begin{tabular}{|c|c|c|c|c|}
\hline \multirow{2}{*}{ Selected parameters } & & \multicolumn{3}{|c|}{ APTE } \\
\hline & & Number & Percentage & p-value \\
\hline \multirow{4}{*}{ ASIA Impairment Scale } & $A I S-A$ & 29 & 76.3 & \multirow{4}{*}{$0.002 *(F)$} \\
\hline & AIS-B & 1 & 33.3 & \\
\hline & AIS-C & 11 & 78.6 & \\
\hline & AIS-D & 5 & 29.4 & \\
\hline WISCI-II & $1-20$ & 19 & 52.8 & 0.086 (Chi) \\
\hline \multirow{2}{*}{ Barthel } & Medium (up to 17) & 16 & 80.0 & \multirow{2}{*}{0.337 (Chi } \\
\hline & Mild (18-20) & 27 & 64.3 & \\
\hline \multirow{2}{*}{ pressure sores reported } & no & 40 & 62.5 & \multirow{2}{*}{0.702 (Chi) } \\
\hline & yes & 6 & 75.0 & \\
\hline spasticity at discharge & Negative & 8 & 47.1 & 0.173 (Chi) \\
\hline \multirow{3}{*}{ Time from injury to questionnaire collection } & Between $10-20$ months & 15 & 32.6 & \multirow{3}{*}{$0.078(\mathrm{St})$} \\
\hline & Between 20 - 30 months & 6 & 13.0 & \\
\hline & Between $30-40$ months & 25 & 54.3 & \\
\hline \multirow{2}{*}{ Gender } & Female & 9 & 64.3 & \multirow{2}{*}{1.000 (Chi) } \\
\hline & Male & 37 & 63.8 & \\
\hline \multirow{2}{*}{ Age } & up to 40 years old & 25 & 71.4 & \multirow{2}{*}{0.294 (Chi) } \\
\hline & $>40$ years old & 21 & 56.8 & \\
\hline \multirow{3}{*}{ Place of residence } & Country & 19 & 70.4 & \multirow{3}{*}{$0.688(F)$} \\
\hline & Small town & 8 & 61.5 & \\
\hline & Big town/city & 19 & 59.4 & \\
\hline \multirow{2}{*}{ Marital status } & Single & 41 & 65.1 & $0714(\mathrm{~F})$ \\
\hline & In a relationship & 5 & 55.6 & $0.114(\mathrm{r})$ \\
\hline effectively in daily life & A moderate amount & 10 & 32.3 & $0.826(F)$ \\
\hline (Question 4 WHOQOL-BREF) & Very much, extremely & 14 & 73.9 & \\
\hline & a little and not at all & 11 & 23.9 & \\
\hline $\begin{array}{l}\text { accepting bodily appearance } \\
\text { (Question } 11 \text { WHOOOL-BREF) }\end{array}$ & Moderately, & 18 & 39.1 & 0.866 (Chi) \\
\hline & Mostly and completely & 17 & 37.0 & \\
\hline & a little and not at all & 4 & 8.7 & \\
\hline $\begin{array}{l}\text { Feeling safe in daily life } \\
\text { (Ouestion } 8 \text { WHOOOL-BREF) }\end{array}$ & A moderate amount, & 15 & 32.6 & 0.407 (Chi) \\
\hline & Very much, extremely & 27 & 58.7 & \\
\hline & Bad and very bad & 7 & 43.75 & \\
\hline $\begin{array}{l}\text { Subjective assessment of financial situation } \\
\text { (Ouestion } 12 \text { WHOOOL-BREF) }\end{array}$ & Average & 13 & 32.5 & $0.774(F)$ \\
\hline & good and very good & 6 & 60.0 & \\
\hline Bemunerative emplovment & employed & 35 & 59.3 & $0115(\mathrm{~F})$ \\
\hline Remunerative employment & not employed & 11 & 84.6 & \\
\hline & Very dissatisfied and dissatisfied and & 28 & 60.9 & \\
\hline Satisfaction with ability to perform daily living activities & Neither satisfied nor dissatisfied & 13 & 28.3 & 0.315 (Chi) \\
\hline & satisfied and very Satisfied & 5 & 10.9 & \\
\hline & Very dissatisfied and dissatisfied & 28 & 60.9 & \\
\hline $\begin{array}{l}\text { Satisfaction with capacity for work } \\
\text { (Question } 18 \text { WHOOOL-BREF) }\end{array}$ & Neither satisfied nor dissatisfied, & 13 & 28.3 & 0.441 (Chi) \\
\hline & Satisfied and very satisfied & 5 & 10.9 & \\
\hline & Unsatisfied & 19 & 41.3 & \\
\hline $\begin{array}{l}\text { Satisfaction with state of health } \\
\text { (Ouestion } 2 \text { WHOOOL-BREF) }\end{array}$ & Neither satisfied, nor unsatisfied & 21 & 45.7 & 0.847 (Chi) \\
\hline & Satisfied & 6 & 13.0 & \\
\hline & Bad and very bad & 6 & 13.0 & \\
\hline $\begin{array}{l}\text { General assessment of patient's quality of life } \\
\text { (Ouestion } 1 \text { WHOOOL-BREF) }\end{array}$ & Neither good, nor bad & 22 & 47.9 & 0.505 (Chi) \\
\hline & Good and very good & 18 & 39.1 & \\
\hline
\end{tabular}

ADL - activities of daily living; AIS - American Spinal Cord Injury Impairment Scale; ASIA - American Spinal Cord Injury; APTE - adherence to prescriptions of therapeutic exercises; Chi - Chi-square test; F- Fisher test; $\mathrm{t}$ - t-Student test; WISCI-II - Walking Index Spinal Cord Injury; $\mathrm{p}$ - statistical significance level. 
Table 3. Correlation of exercise dose assessment vs. meeting APTE criteria, type of physiotherapy and place of APTE implementation

\begin{tabular}{|c|c|c|c|c|c|c|}
\hline & & \multicolumn{5}{|c|}{ Subjective assessment of the exercise dose } \\
\hline & & Completely insufficient & Hardly sufficient & Partially sufficient & Completely sufficient & p-value \\
\hline \multirow{2}{*}{ Meeting the APTE criteria } & No & $7(28.0 \%)$ & $6(24.0 \%)$ & $7(28.0 \%)$ & $5(20.0 \%)$ & \multirow{2}{*}{$0.112(F)$} \\
\hline & Yes & $6(13.0 \%)$ & $5(10.9 \%)$ & $24(52.2 \%)$ & $11(23.9 \%)$ & \\
\hline \multirow[b]{2}{*}{ sources of assistance funding } & Public & $6(17.6 \%)$ & $8(23.5 \%)$ & $14(41.2 \%)$ & $6(17.6 \%)$ & \multirow[b]{2}{*}{$0.339(\mathrm{~F})$} \\
\hline & Public and private & $4(16.7 \%)$ & $2(8.3 \%)$ & $12(50.0 \%)$ & $6(25.0 \%)$ & \\
\hline \multirow{3}{*}{ Place where exercise is done } & Patient's home & $9(27.3 \%)$ & $6(18.2 \%)$ & $10(30.3 \%)$ & $8(24.2 \%)$ & \multirow{3}{*}{$0.033^{*}(\mathrm{~F})$} \\
\hline & $\begin{array}{l}\text { Patient's home and } \\
\text { rehabilitation centre }\end{array}$ & $1(4.0 \%)$ & $5(20.0 \%)$ & $14(56.0 \%)$ & $5(20.0 \%)$ & \\
\hline & Rehabilitation centre & $1(9.1 \%)$ & $0(0.0 \%)$ & $7(63.6 \%)$ & $3(27.3 \%)$ & \\
\hline
\end{tabular}

APTE - adherence to prescriptions of therapeutic exercises; $F$ - Fisher test; $p$ - statistical significance level.

APTE. In the presented study, APTE with the use of technical devices was not assessed. In the literature, financial problems and long waiting time for physiotherapy were not mentioned as the causes of non-APTE. This may be the result of the better economic status of the Americans and Canadians in comparison with the inhabitants of Poland.

In the presented study, the SCI severity showed a negative correlation with APTE (Tab. 2), however, other researchers did not notice such correlations [18]. Dolbow et al. showed a statistically insignificant difference in APTE between subjects with tetraplegia and paraplegia to the disadvantage of the latter [18]. (tetraplegia = paraplegia $-\mathrm{MT}$ ), It must be remembered, however, that the group studied by Doblow et al. comprised only of 17 participants, and the APTE assessment was performed only with regard to continuation of exercises with the use of a bicycle ergometer. Therefore, it is difficult to compare these results with the current study. Ditor et al. emphasise a significant effect of pain and increased level of stress after exercises as factors showing a significant negative correlation with APTE [20]. They did not analyse other medical conditions,(.g. spasticity or pressure ulcers.

Dolbow et al. noticed that younger participants insignificantly more often reported APTE [18]. The presented analysis shows a similar result and also demonstrates that there is no statistically significant correlation between APTE and other studied socio-demographic factors (Tab. 2). In the current study, the time from discharge did not have a significant effect on APTE, nor was there any verification of the level of resigning from exercises in individual patients, depending on the period after leaving the acute phase.

47 subjects (65.3\% of all respondents) assessed the dose of their exercises as partially or completely sufficient, which was significantly correlated with the place of physiotherapy (correlation between positive answers regarding the applied dose of physiotherapy and APTE in various rehabilitation centres). However, no statistically significant correlations between the subjective assessment of exercise dose and APTE were observed. In the light of recommendations regarding exercising by SCI subjects of 2015 [12], this may indicate a lack of awareness of the patients in relation to assessment of needs and necessity of APTE. This may results from a gap in the system of supervision and counselling in the aspect of encouraging patients to participate in the exercises, which may be observed in the long-term care of SCI patients in Poland [27].
Counselling support could at least help with increasing the patient's motivation for APTE. Other authors report this kind of problem which at the same time are barriers to performing exercises and the reintegration of subjects after SCI $[28,29]$. Pallatier et al. emphasise the necessity to adjust the system of supervision and counseling, and indicate the need to develop a strategy of health promotion as a factor affecting APTE [15]. Multicentre cooperation and unification of rehabilitation teams, including psychologists, may have similar significance [30].

Reduced frequency of exercises combined with increased time from leaving the rehabilitation centre [31], poor engagement and low regularity of exercises, as well as suboptimal patient awareness of the necessity to train, result in increased financial costs borne by persons with SCI in relation to performing exercises with physiotherapeutic supervision. In the presented study, $51.4 \%$ of the study subjects reported own financial contribution in performing the recommended exercises. The possibilities of reimbursed for in-home physiotherapy are insufficient, and $73.6 \%$ of patients did not have this type of therapy in the follow-up period. In Poland, there is a limit on reimbursing interventions performed by the physiotherapist in the patient's home, which is established by the State as up to 80 days during the calendar year [32]. In the group of subjects who had this type of therapy, $57.69 \%$ had full-time therapy and the rest had part-time therapy. Since public rehabilitation is unavailable, patients have no choice but to turn to private physiotherapy.

In the current study, no correlation was have observed between APTE and the respondents' QOL and their assessment of health well-being. Evaluation of the level of quality of life is the most commonly used method to assess the improvement in a patient's health after various injuries or diseases [33-35]. Also, no correlation was observed between the functioning of patients with SCI in particular spheres of the QOL - physical, psychological, social and environmental, and APTE. However, studies of Hicks et al., and Ditor et al. show a positive correlation between APTE and QOL after SCI $[14,15]$. These studies, however, were based on a different scale of QOL assessment, the Perceived Quality Of Life (PQOL), and the groups of study subjects were less numerous: Hicks et al. - 34 participants, and Ditor et al. - 7 participants), compared to the current study - 72 participants.

Study limitations. The study was limited by the inability to perform an objective assessment of the patients' state of 
health and APTE, and that the receipt of information from the patients using questionnaire method was not sufficiently coherent. The study group had some signs of impurity, but in the opinion of the authors this did not affect the results in a significant way. It is worth mentioning that elimination of group impurity requires further and multi-centre studies in larger population.

The present study does not include all causes of non-APTE, e.g. personal factors. The objective of further studies will be to complete this information.

Although using the same time of data collection according to QUADAS-2 would have improved the study, on the other hand, it is worth noting that in such groups of patients it is common to meet some difficulties in cooperation, caused by SCI patients often lacking sufficient motivation to adhere to time of questionnaire response.

The methodology of presented study did not allow a direct comparison of the results with those obtained by other authors.

\section{CONCLUSIONS}

In the study group, $63.9 \%$ of the subjects between 10.5 and 41 months of discharge from the rehabilitation department showed APTE. The basic place to perform exercises as instructed by hospital was the subject's home. Limited access to reimbursed environmental therapy resulted in an increased cost of exercises supervised by commerciallyemployed physiotherapists. A positive correlation was shown between the ability to perform the activities of daily living and the more frequent purchase of physiotherapeutic services in order to perform exercises. In the study population, APTE did not correlate with the QOL of patients after SCI. The current gaps in the system of supervision and counselling of subjects with SCI in Poland, necessitate changes in the health care system regarding the above-mentioned subjects. Multicentre cooperation and unification of rehabilitation teams, including psychologists, may have similar significance. Developing one standardized programme of rehabilitation including home training programme seems to be necessary to improve patients' QOL as to-date there is no international consensus.

\section{REFERENCES}

1. Sweis R, Biller J. Systemic Complications of Spinal Cord Injury. Curr Neurol Neurosci Rep. 2017; 17: 1-8.

2. Rapidi CA, Tederko P, Moslavac S, Popa D, Branco CA, Kiekens C et. al. Professional Practice Committee of the UEMS-PRM Section. Evidence-based position paper on Physical and Rehabilitation Medicine (PRM) professional practice for persons with spinal cord injury. The European PRM position (UEMS PRM Section). Eur J Phys Rehabil Med. 2018; 54: 797-807.

3. Skelton F, Hoffman JM, Reyes M, Examining health-care utilization in the first year following spinal cord injury. J Spinal Cord Med. 2015; 38: 690-695.

4. Jensen MP, Molton IR, Groah SL, Cmapbell ML, Charilifue S, Chiodo A, et al. Secondary health conditions in individuals aging with SCI: terminology, concepts and analytic approaches. Spinal Cord. 2012; 50: $373-378$

5. Hayden JA, van Tulder MW, Tomlinson G. Systematic review: strategies for using exercise therapy to improve outcomes in chronic low back pain. Ann Inter Med. 2005; 142: 776-785.

6. Campbell R, Evans M, Tucker M, Quilty B, Dieppe P, Donovan J. Why don't patients do their exercises? understanding non-compliance with physiotherapy in patients with osteoarthritis of the knee. J Epidemiol Community Health. 2001; 55: 132-138.

7. Friedrich M, Gittler G, Halberstadt Y, Cermak T, Heiller I. Combined exercise and motivation program: effect on the compliance and level of disability of patients with chronic low back pain: a randomized controlled trial. Arch Phys Med Rehabil. 1998; 79: 475-487.

8. Harvey LA. Physiotherapy rehabilitation for people with spinal cord injuries. J Physiother. 2016; 62(1): 4-11.

9. Zbogar D, Eng JJ, Miller WC, Krassioukov AV, Verrier MC. Movement repetitions in physical and occupational therapy during spinal cord injury rehabilitation. Spinal Cord. 2017; 55(2): 172-179.

10. Scivoletto G, Miscusi M, Forcato S, et al. The Rehabilitation of Spinal Cord Injury Patients in Europe. Acta Neurochir Suppl. 2017; 124: 203-210.

11. Côté MP, Murray M, Lemay MA. Rehabilitation Strategies after Spinal Cord Injury: Inquiry into the Mechanisms of Success and Failure. J Neurotrauma. 2017; 34(10): 1841-1857.

12. Evans N, Wingo B, Sasso E, Hicks A, Gorgey AS, Harness E. Exercise Recommendations and Considerations for Persons With Spinal Cord Injury. Arch Phys Med Rehabil. 2015; 96: 1749-1750.

13. Sluijs EM, Knibbe JJ. Patient Compliance with Exercise: Different Theoretical Approaches to Short-Term and Long-Term Compliance, Patient Educ Couns. 1991; 11: 191-204.

14. Sabate E. Adherence to Long Term Therapies - Evidence for Action. (Geneva. World Health Organisation 2003 WHO/NLM/W85).

15. Jack K, McLean SM, Moffett JK, Gardiner E. Barriers to treatment adherence in physiotherapy outpatient clinics: A systematic review. Man Ther. 2010; 15: 220-228.

16. Pelletier CA, Latimer-Cheung AE, Warburton DE, Hicks AL. Direct referral and physical activity counselling upon discharge from spinal cord injury rehabilitation. Spinal Cord. 2014; 52: 392-395.

17. Pelletier CA, Totosy de Zepentnek JO, MacDonald MJ, Hicks AL. A 16-week randomized controlled trial evaluating the physical activity guidelines for adults with spinal cord injury. Spinal Cord. 2015, 53: 363-367.

18. Dolbow DR, Gorgey AS, Ketchum JM, Moore JR, Hackett LA, Gater DR. Exercise adherence during home-based functional electrical stimulation cycling by individuals with spinal cord injury. Am J Phys Med Rehabil. 2012; 91: 922-930.

19. Hicks AL, Martin KA, Ditor DS, Latimer AE, Craven C, Bugaresti J et al. Long-term exercise training in persons with spinal cord injury: effects on strength, arm ergometry performance and psychological well-being. Spinal Cord. 2003; 41: 34-43.

20. Ditor DS, Latimer AE, Ginis KA, Arbour KP, McCartney N, Hicks AL. Maintenance of exercise participation in individuals with spinal cord injury: effects on quality of life, stress and pain. Spinal Cord. 2003; 41: 446-450.

21. Dietz V, Fouad K. Restoration of sensorimotor functions after spinal cord injury. Brain. 2014; 137(3): 654-67.

22. Wołowicka L. Przegląd badań nad jakością życia chorych po intensywnej terapii dorosłych. In: Wołowicka L. (eds.) Jakość życia w naukach medycznych. (Wyd. UM Poznań. 2001), 193-201.

23. Collin C, Wade DT, Davies S, Horne V. The Barthel ADL Index: a reliability study. Int Disabil Stud., 1988; 2: 61-63.

24. Opara J, Mehlich K., Bielecka A. Walking index for spinal cord injury. Ortop Traumatol Rehabil. 2007; 9: 122-127.

25. Kirshblum SC, Burns SP, Biering-Sorensen F, Donovan W, Graves $\mathrm{DE}$, Jha $\mathrm{A}$, Johansen $\mathrm{M}$ et al. International standards for neurological classification of spinal cord injury (revised 2011). J Spinal Cord Med. 2011: 34: 535-546.

26. Ginis KAM, Hicks AL, Latimer AE, Warburton DER, Bourne C, Ditor DS et al. The development of evidence-informed physical activity guidelines for adults with spinal cord injury. Spinal Cord. 2011; 49: 1088-1096.

27. Tederko P, Jagodziński R, Krasuski M, Tarnacka B. People with spinal cord injury in Poland. Am J Phys Med Rehabil. 2017; 96: 102-105.

28. Vissers M, van den Berg-Emons R, Sluis T, Bergen M, Stam H, Bussman $\mathrm{H}$. Barriers to and facilitators of everyday physical activity in persons with a spinal cord injury after discharge from the rehabilitation centre. J Rehabil Med. 2008; 40: 461-467.

29. Scelza WM, Kirshblum SC, Wuermser LA, Ho CH, Priebe MM, Chiodo AE. Community reintegration after spinal cord injury. Spinal cord injury medicine. 4. Community reintegration after spinal cord injury. Arch Phys Med. Rehabil. 2007; 88: 71-75.

30. Tederko P, Mycielski J, Angerova Y, et al. Role of diversity in assembling of rehabilitation teams in Central Europe [published online ahead of print, 2020 Jan 14]. Eur J Phys Rehabil Med. 2020;10.23736/S19739087.20.05904-3. doi:10.23736/S1973-9087.20.05904-3. 
31. Anneken V, Hanssen-Doose A, Hirschfeld S, Scheuer T, Thietje R. Influence of physical exercise on quality of life in individuals with spinal cord injury. Spinal Cord. 2010; 48: 393-399.

32. Minister of Health's Notice of 30 January 2018 on publication of the consolidated text of the Regulation of the Minister of Health on guaranteed benefits in the field of therapeutic rehabilitation, Polish Journal of Laws Dz.U.2018, item 465,

33. http://isap.sejm.gov.pl/isap.nsf/download.xsp/WDU20180000465/O/ D20180465.pdf

34. Kuret Z, Burger H, Vidmar G, Maver T. Adjustment to finger amputation and silicone finger prosthesis use. Disabil Rehabil. 2019; 41(11): 1307-1312.
35. Robins JMW, Boyle A, McCune K, Lodh R, Goodden JR. Quality of life after selective dorsal rhizotomy: an assessment of family-reported outcomes using the CPQoL questionnaire published online ahead of print, 2020 Feb 24]. Childs Nerv Syst. 2020; 10.1007/s00381-02004546-1.

36. Schmidberger J, Steinbach J, Schlingeloff P, Kratzer W, Grüner B. Surgery versus conservative drug therapy in alveolar echinococcosis patients in Germany - A health-related quality of life comparison. Food Waterborne Parasitol. 2019; 16: e00057. Published 2019 May 30. doi:10.1016/j.fawpar.2019.e00057. 